\title{
Cortical Venous Thrombosis Complicating Tubercular Meningitis
}

\author{
Jahnvi Dhar ${ }^{1}$, Garvit Chhabra², Lokesh Khandelwal ${ }^{3}$, S. Anuradha² and Akshee Batra ${ }^{2}$ \\ ${ }^{1}$ Department of Gastroenterology, Institute of Medical Education \& Research, Chandigarh, India \\ ${ }^{2}$ Department of Medicine, Maulana Azad Medical College, New Delhi, India \\ ${ }^{3}$ Department of Cardiology, Maulana Azad Medical College, New Delhi, India
}

\begin{abstract}
Cortical venous thrombosis (CVT) mostly occurs due to a hypercoagulable state. Infection- related CVT is very rare and is a medical emergency associated with a very high mortality rate. It has been described with bacterial and fungal infections; but only a few isolated case reports of CVT related to tubercular meningitis (TBM) exist. Only six documentations of CVT, as a complication of TBM, exist in the literature. Here, we report a case of a young girl with TBM who developed CVT as a complication.
\end{abstract}

Key Word: Tuberculosis, Meningitis, Cerebral venous thrombosis.

How to cite this article: Dhar J, Chhabra G, Khandelwal L, Anuradha S, Batra A. Cortical Venous Thrombosis Complicating Tubercular Meningitis. J Coll Physicians Surg Pak 2021; 31(02):221-224.

\section{INTRODUCTION}

Tuberculosis (TB) is the major infectious disease worldwide, with an estimated 1.7 million deaths globally in $2016 .{ }^{1}$ Central nervous system (CNS) TB may present as tubercular meningitis (TBM), meningoencephalitis, tuberculomas, abscesses and stroke due to tubercular vasculitis. TBM has important, serious complications like syndrome of inappropriate antidiuretic hormone (SIADH), hydrocephalus (mostly non-communicating), stroke (usually infarcts), cranial nerve palsies, seizures, diabetes insipidus due to hypothalamic involvement, tuberculoma and myeloradiculopathy. ${ }^{2}$ Cerebral venous thrombosis (CVT) is a condition characterised by the presence of a thrombus in the dural venous sinuses. CVT is usually a manifestation of a hypercoagulable state and infectious conditions causing CVT, which is uncommon. Theassociation of TBM with CVT is extremely rare; and till date, only six cases are published in world literature. We report a 16-year girl with TBM who developed CVT as a complication.

\section{CASE REPORT}

A 16-year female, resident of Uttar Pradesh, India presented to the Medicine Emergency of Lok Nayak Hospital, New Delhi, India with complaints of high grade fever, headache and vomiting for three days, followed by altered sensorium for one day.

Correspondence to: Dr. Garvit Chhabra, Department of Medicine, Maulana Azad Medical College, New Delhi, India

E-mail: garvit.chhabra26@gmail.com

Received: April 10, 2019; Revised: April 30, 2020;

Accepted: July 06, 2020

DOI: https://doi.org/10.29271/jcpsp.2021.02.221
Fever was high grade, continuous and associated with chills and rigors. There was no history of cough, coryza, breathlessness, abdominal pain, diarrhoea, jaundice, burning micturition, decreased urine output, joint pains or swelling, rash or bleeding from any site or ear discharge. Further, there were no complaints of seizures, blurring of vision, facial deviation, difficulty in swallowing or speech or weakness of any part of the body. Herpast and personal history was insignificant

On examination, the patient was conscious but disoriented to time, place and person, febrile (temperature of $101^{\circ} \mathrm{F}$ ) and pale. There was no lymphadenopathy; and rest of the general physical examination was unremarkable. Neurological examination depicted neck rigidity along with a positive Kernig's sign. Bilateral pupils were normal in size and reaction and plantar responses were flexor. The tone, power and deep tendon reflexes in the upper and lower limbs were normal. The respiratory, cardiovascular and abdominal systems were normal on examination.

Investigations revealed haemoglobin: $9.5 \mathrm{~g} / \mathrm{dL}$, total leucocyte count: $11,600 / \mathrm{cu} \mathrm{mm}$ with a differential count of $80 \%$ polymorphs and 20\% lymphocytes and platelet count of 167,000/cumm. Erythrocyte sedimentation rate was $47 \mathrm{~mm} /$ 1st hour. Rapid diagnostic test for malaria, peripheral smear for malarial parasites, and typhidot IgM were negative. The chest X-ray and non-contrast computed tomography (CT) (NCCT) head was normal. Cerebrospinal fluid (CSF) analysis revealed total cells: 200 cells with $70 \%$ polymorphs, sugar 26 $\mathrm{mg} / \mathrm{dl}$ (simultaneous blood sugar $107 \mathrm{mg} / \mathrm{dl}$ ) with a protein of $116 \mathrm{mg} / \mathrm{dl}$. The CSF adenosine deaminase (ADA) was $5.6 \mathrm{U} / \mathrm{ml}$. 
Table I: Previously reported cases of cortical venous thrombosis complicating tuberculous meningitis. ${ }^{8-13}$

\begin{tabular}{|c|c|c|c|c|}
\hline S. No & Age/sex & Presenting complaints & Radiological findings on MRI + MRV & Outcome \\
\hline $1 .^{8}$ & $\begin{array}{l}26 \text { years/ } \\
\text { Male }\end{array}$ & $\begin{array}{l}\text { Fever - } 4 \text { months } \\
\text { Headache - } 1 \text { months } \\
\text { Diplopia - } 15 \text { days } \\
\text { Altered sensorium with seizures - } \\
2 \text { days }\end{array}$ & $\begin{array}{l}\text { Non communicating hydrocephalus with } \\
\text { leptomeningeal enhancement. Superior and inferior } \\
\text { sagittal sinus narrowing with increased collaterals. }\end{array}$ & Survived \\
\hline $2 .^{9}$ & $\begin{array}{l}1 \text { month/ } \\
\text { female }\end{array}$ & $\begin{array}{l}\text { Fever - } 1 \text { month } \\
\text { Headache, drowsiness - } 8 \text { days } \\
\text { Seizures - } 1 \text { day }\end{array}$ & $\begin{array}{l}\text { Vasculitic infarcts; bilateral moya-moya pattern of } \\
\text { arteriopathy; thrombosis of the left transverse } \\
\text { sinus. }\end{array}$ & Survived \\
\hline $3 .^{10}$ & $\begin{array}{l}\text { Case series: } \\
3 \text { women } \\
(33,31,31 \\
\text { years) }\end{array}$ & & $\begin{array}{l}\text { Sagittal sinus ( } 2 \text { cases), lateral sinus ( } 2 \text { cases) and } \\
\text { transverse sinus ( } 1 \text { case) thrombosis }\end{array}$ & All survived \\
\hline $4 .^{11}$ & $\begin{array}{l}20 \text { year/ } \\
\text { female }\end{array}$ & $\begin{array}{l}\text { Fever, headache, vomiting - } 4 \\
\text { days }\end{array}$ & Thrombosis of the left transverse and sigmoid sinus & Died \\
\hline $5 .^{12}$ & $\begin{array}{l}61 \text { year/ } \\
\text { male }\end{array}$ & $\begin{array}{l}\text { Fever, headache, multiple cranial } \\
\text { nerve palsies - } 1 \text { month }\end{array}$ & $\begin{array}{l}\text { Superior sagittal sinus thrombosis; patient had } \\
\text { disseminated tuberculosis (TBM + Pulmonary) }\end{array}$ & Survived \\
\hline $6 .^{13}$ & $\begin{array}{l}48 \text { year/ } \\
\text { female }\end{array}$ & $\begin{array}{l}\text { Fever, headache }-2 \text { months } \\
\text { Drowsiness - } 10 \text { days }\end{array}$ & Superficial cortical venous thrombosis & Survived \\
\hline
\end{tabular}

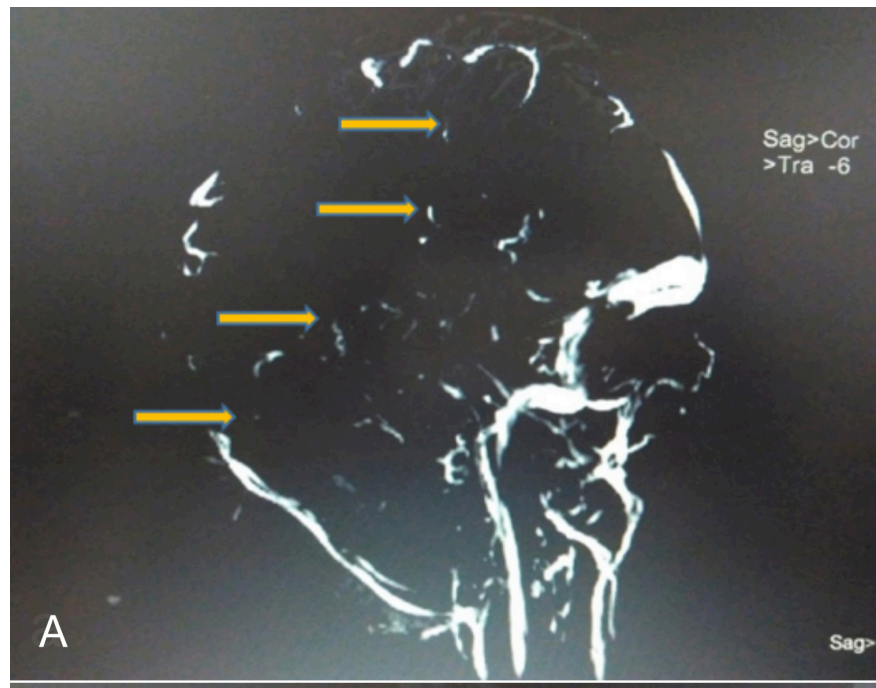

B

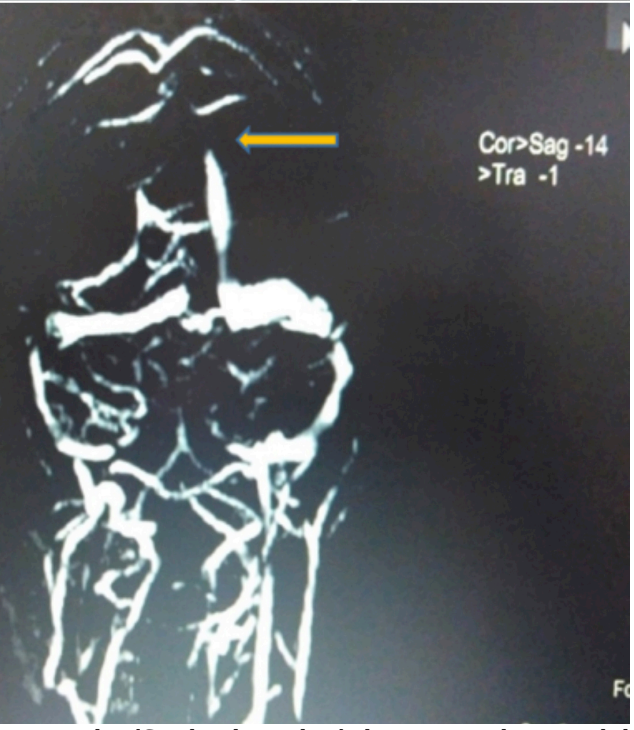

Figure 1: (A) MR venography (Sagittal section) demonstrating partial visualisation with filling defects (yellow arrows) of superior sagittal sinus, bilateral sigmoid sinus, and proximal left transverse sinus with non-visualisation of inferior sagittal and straight sinus. (B) Coronal section: partial visualisation with filling defect (yellow arrow) of superior sagittal sinus and bilateral sigmoid sinus suggestive of cortical venous thrombosis (CVT).
In view of a short clinical history and CSF findings, a provisional diagnosis of acute pyogenic meningitis was made and the patient was started on antibiotics, decongestants and steroids. Despite this, the patient's condition did not improve and she remained unconscious.

On further investigations, urine and blood culture were negative. CSF bacterial culture, herpes simplex virus and Japanese encephalitis virus serology, dengue NS1Ag with serology, antinuclear antibody, human immunodeficiency virus (HIV), hepatitis B surface antigen (HBsAG) and anti-hepatitis $C$ virus (HCV) antibodies were negative. The fundus examination was normal with no evidence of papilledema. The CSF (CBNAAT) cartridge-based nucleic acid amplification test was positive for mycobacterium tuberculosis and it was rifampicin sensitive. A final diagnosis of TBM was made. Anti-tubercular therapy with injection dexamethasone was initiated. Eight weeks later, the CSF culture on L-J (Lowenstein Jensen) medium grew mycobacterium tuberculosis.

The patient improved clinically over the next few days. On day- 6 of admission, the patient had three episodes of generalised tonic clonic seizures and developed a left 6th nerve palsy. The fundus examination now revealed presence of papilledema. However, the magnetic resonance imaging (MRI) brain with contrast was normal. The MRI venography revealed partial visualisation with thrombosis of superior sagittal sinus, bilateral sigmoid sinuses and proximal left transverse sinus along with non-visualisation of inferior sagittal and straight sinus, suggestive of CVT, as shown in Figure 1.

In view of cortical venous thrombosis, anticoagulants (warfarin) were initiated at $5 \mathrm{mg} O D$ and the dose was titrated till the INR was achieved at 2.5 after a few days. The thrombophilia profile (protein $\mathrm{C}$ and $\mathrm{S}$ and homocysteine levels) was normal. The patient gradually improved over the next week and made complete neurological recovery.

\section{DISCUSSION}

CVT is defined as the presence of a thrombus in the dural sinuses draining the brain, seen as a filling defect or pres- 
ence of a blood clot on MRI brain. ${ }^{4}$ MR venography (sensitivity $84-100 \%$ ) is considered the diagnostic test of choice for CVT. ${ }^{2}$ It affects about 5 people per million population and accounts for $0.5 \%$ of all strokes. ${ }^{3,4}$

The clinical presentation of CVT can be as one of three categories: intracranial hypertension (manifesting as headache, vomiting, papilledema or visual problems), focal neurological deficits with seizures or encephalopathy (with multifocal signs and mental status changes). ${ }^{5}$

Virchow's triad, namely vascular endothelial damage, stasis and hypercoagulability act synergistically to cause vascular thrombosis. Defects in coagulation cascade are the most common cause of CVT in males; and use of oral contraceptive pills and pregnancy is implicated most commonly in females. Factor $V$ Leiden mutation is the most frequently inherited thrombophilia worldwide and is responsible for about $20 \%$ cases of CVT. ${ }^{5}$ Vascular endothelial damage leading to CVT is relatively uncommon. It results from infections (bacterial, TB, fungal), tumors, trauma and inflammatory conditions. ${ }^{2}$ Infections account for $<6 \%$ of all the cases of CVT. CVT, associated with TBM, is even rarer with an estimated incidence of $0.67 / 100,000$ per year. $^{6}$

Though India has the highest TB burden in the world ${ }^{1}$, the association of TBM with CVT has been scarcely reported., The postulated mechanisms of CVT in TB include endothelial injury due to inflammatory response, sluggish venous flow and increased platelet aggregation and release of pro-coagulant factors. ${ }^{6}$ The brain microglia mounts a robust immune response to mycobacterium tuberculosis infection by releasing several cytokines and chemokines like TNF- $\alpha$, IL- 6 , IL-1ß, CCL2, CCL5 and CXCL10. ${ }^{7}$ Tumour necrosis factoralpha and interleukin- 6 have been found to have an additive effect in pro-coagulant activity on human endothelial cells by promoting platelet aggregation and thrombosis. ${ }^{7}$ Intracranial sinuses being a low-pressure system without valves, promote blood stasis. The above-mentioned mechanisms also lead to endothelium injury in intracranial veins. ${ }^{1,5}$

A review of literature revealed only six published cases of CVT solely attributable to TBM, with no evidence of TB elsewhere, as summarised in Table I.

In the above-mentioned cases, excluding one, all of them had prolonged duration of symptoms of fever and headache along with evidence of TBM, like meningeal enhancement, hydrocephalus and infarcts on MRI brain with demonstration of thrombosis on MRI venography. In our case, the young girl had an unusual presentation with a short duration of symptoms, but had CSF CBNAAT demonstrable along with CSF culture documenting mycobacterium tuberculosis. She had evidence of widespread thrombosis of the cortical sinuses on MR venography. The prompt diagnosis and early institution of treatment led to a favorable outcome and complete neurological recovery.
TBM, associated with myriad neurological features and CVT, is one of the rare complications. CVT must be entertained as a differential diagnosis in patients with TBM, who show worsening of clinical features and/or develop new neurological signs.

\section{PATIENT'S CONSENT:}

Informed consent was obtained from the patient to publish the data concerning the case and making sure that patient information was unidentifiable.

\section{CONFLICT OF INTEREST:}

No conflicts of interest to declare.

\section{AUTHORS' CONTRIBUTION:}

JD, GC, LK: Topic conception; data gathering and analysis; manuscript preparation, review, revisions, and editing.

SA: Manuscript preparation, review, revisions, and editing. $A B$ : Data gathering and analysis; manuscript preparation, review, revisions and editing.

\section{REFERENCES}

1. World Health Organisation. Global tuberculosis report 2017 [cited 2020 Mar 24]. Available from: http://apps.who.int/iris/ bitstream/handle/10665/259366/9789241565516-Peng.pd$f$ ? sequence $=1$.

2. Marx G, Chan E. Tuberculous meningitis: Diagnosis and treatment overview. Tuberc Res Treat 2011; 2011:1-9. doi: 10.1155/2011/798764.

3. Coutinho J, Zuurbier S, Aramideh M, Stam J. The incidence of cerebral venous thrombosis. Stroke 2012; 43(12):3375-7. doi.org/10.1161/STROKEAHA.112.671453.

4. Bousser M, Ferro J. Cerebral venous thrombosis: An update. Lancet Neurol 2007; 6(2):162-70. doi.org/10.1016/ S1474-4422 (07)70029-7.

5. Sébire G, Tabarki B, Saunders DE, Liesner LR, Martin CS, Husson $B$, et al. Cerebral venous sinus thrombosis in children: Risk factors, presentation, diagnosis and outcome. Brain 2005; 128(3):477-489. doi: 10.1093/brain/ awh412.

6. Cherian A, Thomas S. Central nervous system tuberculosis. African Health Sciences 2011; 11(1):116-27.

7. Rock R, Olin M, Baker C, Molitor T, Peterson P. Central nervous system tuberculosis: Pathogenesis and clinical aspects. Clin Microbiol Rev 2008; 21(2):243-61. doi: 10.1128/ CMR.00042-07.

8. Verma R, Lalla R, Patil T, Tiwari N. A rare presentation of cerebral venous sinus thrombosis associated with tubercular meningitis. BMJ Case Rep 2013; 2013(aug05 1): bcr2013009892-bcr2013009892. doi: 10.1136/bcr-2013009892.

9. Ranjith Kumar M, Saini L, Kaushik JS, Chakrabarty B, Kumar A, Gulati S. A combination of moyamoya pattern and cerebral venous sinus thrombosis: A case of tubercular vasculopathy. J Trop Pediatr 2015; 61(5):393-6. doi: 10.1093/trope$\mathrm{j} / \mathrm{fm}$ 036.

10. Guenifi W, Boukhrissa H, Gasmi A, Rais M, Ouyahia A, 
Hachani A, et al. Thromboses veineuses cérébrales au cours de la méningo-encéphalite tuberculeuse. J Mal Vasc 2016; 41(3):210-4. doi: 10.1016/j.jmv.2016.03.002.

11. Ramdasi R, Mahore A, Kawale J, Thorve S. Cerebral venous thrombosis associated with tuberculous meningitis: A rare complication of a common disease. Acta Neurochirurgica 2015; 157(10):1679-80. doi: 10.1007/s00701-015-2493-

12. Finsterer J, Kladosek A, Nagelmeier I, Becherer A, Matula C,
Stradal K et al. Chronic granulomatous meningitis with multiple cranial nerve lesions, hydrocephalus, stroke, sinus thrombosis, and epilepsy. South Med J 2000; 93(11): 1108-1111.

13. Elkesiassy A, Weill A, Miaux Y, Savin D, Duverneuil NM, Chiras J. Dilatation of deep medullary veins in cortical venous occlusion due to focal tuberculous leptomeningitis. Neuroradiology 1997; 39(10):705-7. doi: 10.1007/s0023 40050490. 